934

\section{ARTIFICIAL LIVER SUPPORT IN CHILDREN WITH FULMINANT HEPATIC FAILURE: OUR EXPERIENCE}

\author{
M. Corno ${ }^{1}$, E. Bonanomi ${ }^{1}$, I. Pellicioli ${ }^{1}$, A. Tartufari ${ }^{1}$, \\ V. Corno ${ }^{2}$, D. Codazzi ${ }^{1}$
}

${ }^{1}$ Pediatric Intensive Care Unit - Ospedali Riuniti di Bergamo, Bergamo, Italy, ${ }^{2}$ General Surgery III Liver and Lung Transplantation Center- Ospedali Riuniti di Bergamo, Bergamo, Italy

Background: Fulminant hepatic failure (FHF) is characterized by the development of encephalopathy and impaired synthetic liver capacity in patients with previous normal liver function or well compensated liver disease. Orthotopic liver transplantation (OLTx) seems to be the only therapy proven to improve patient survival in most cases. The role of artificial liver support encompasses toxin removal and the reversal of the inflammatory process.

Design: Retrospective analysis in children affected by FHF who underwent artificial liver support.

Setting: Pediatric Intensive Care Unit in a Tertiary referral Hospital.

Patients: 10 children with FHF were admitted to our PICU from January 12005 to December 312008.

Results: Fifty per cent of patients were female and mean age was 57 months $\pm 9,5$. Most common cause of FHF was autoimmune $(50 \%)$ followed by drugs and toxins induced (40\%). The mean Pediatric End-Stage Liver Disease (PELD) score was $33 \pm 9$ and the electroencephalography recording showed severe signs of encephalopaty in all the patients. All patients but one underwent continuous veno-venous hemodiafiltration (CVVH). Delay from suspected diagnosis to the beginning of the depuration therapy ranged from few hours to 3 days. 5 patients underwent OLTx. All patients were dicharged with a good neurological status.

Conclusions: The most important factor in predicting survival in FHF are the degree of encephalopathy, the patient's age, and the cause of FHF. Artificial support systems did not appear to affect the mortality rate and may "bridge" patients to OLTx or spontaneous recovery.

\section{COMPARATIVE CLINICAL-GENETIC HEALTH ANALYSIS OF CHILDREN LIVING IN VARIOUS ECOLOGICALLY UNFAVORABLE AREAS}

\author{
M.V. Appasova, S.V. Choy \\ Department of Paediatrics, Kazakh National \\ Medical University, Almaty, Kazakhstan
}

The aim of the research is to analyze clinical-genetic parameters of health in children living in regions with various ecological troubles for elaboration of optimum methods of combined chronic pathology and chromosomal damages development forecast. This research is devoted to health examination of 120 children living in the region of the Semipalatinsk nuclear ex-range, 203 children living in the Aral Sea region (the basic groups) and 100 children living in the region of relevant well being (control group), aged 7-15 y. Children underwent complex clinical, functional and instrumental health examination, account of minor anomalies of development (MAD) and cytogenetic investigation. Three and more chronic diseases are diagnosed in children from the Semipalatinsk nuclear ex-range and from the Aral Sea region authentically more often than in control group. The prevalence of urinary system diseases and lungs pathology is determined in group from the Aral Sea region. Incidence of congenital malformations of development considerably doesn't differ in children from the Semipalatinsk nuclear range and from the Aral Sea region. The general incidence of chromosomal aberrations is $1,86 \pm 0,09$ in children from the Semipalatinsk nuclear ex-range and 1,90 $\pm 0,09$ - from the Aral Sea region, that is three times more often than in control group $(0,62 \pm 0,07)$.. Correlation between the level of MAD and quantity of chronic diseases in the Aral Sea region is $r=0,91$ 0,96 and in the Semipalatinsk region is $r=0,86-0,96$. Correlation between the level of MAD and level of chromosomal aberrations in the Aral Sea region is $r=0,99$ and in the Semipalatinsk is $r=0,99$. 